\title{
Epidermal Cyst on the Face of a Child, Clinically and Dermoscopically Mimicking Pilomatricoma
}

\author{
Jelena Krtanjek ${ }^{1}$, Ivana Ilic ${ }^{2}$, Mateja Kendel ${ }^{3}$, Ruzica Jurakic Toncic ${ }^{4}$
}

\author{
1 Division of Dermatology and Venereology, General Hospital Varazdin, Varazdin, Croatia \\ 2 Department of Pathology and Cytology, University Hospital Centre Zagreb, Zagreb, Croatia \\ 3 Division of Dermatology and Venereology, County Hospital Cakovec, Cakovec, Croatia \\ 4 University Department of Dermatology and Venereology, University Hospital Centre Zagreb, University of Zagreb School of Medicine, \\ Zagreb, Croatia
}

Key words: pilomatricoma, epidermal cyst, dermoscopy

Citation: Krtanjek J, Ilic I, Kendel M, Jurakic Toncic R. Epidermal cyst on the face of a child, clinically and dermoscopically mimicking pilomatricoma. Dermatol Pract Concept. 2019;9(1):36-37. DOI: https://doi.org/10.5826/dpc.0901a09

Published: January 31, 2019

Copyright: 02019 Krtanjek et al. This is an open-access article distributed under the terms of the Creative Commons Attribution License, which permits unrestricted use, distribution, and reproduction in any medium, provided the original author and source are credited.

Funding: None.

Competing interests: The authors have no conflicts of interest to disclose.

Authorship: All authors have contributed significantly to this publication.

Corresponding author: Ruzica Jurakic Toncic, MD, University Department of Dermatology and Venereology, University Hospital Centre Zagreb, University of Zagreb, School of Medicine, Salata 410000 Zagreb, Croatia. Email: rjtoncic@gmail.com

\section{Introduction}

We present a case of an epidermal cyst on the face of a child, clinically and dermoscopically mimicking pilomatricoma. Pilomatricoma, also called pilomatrixoma or calcifying epithelioma of Malherbe, is a benign skin tumor and one of the most common causes of superficial head and neck masses in children and young adults [1]. It usually manifests as a solitary, asymptomatic, firm nodule on the face (especially eyelids and eyebrows), scalp, neck, or arms [1]. Common differential diagnoses for head and neck pilomatricoma include sebaceous cyst, ossifying hematoma, giant cell tumor, chondroma, dermoid cyst, foreign body reaction, degenerating fibroxanthoma, metastatic bone formation, and osteoma cutis [1]. Pilomatricoma-like changes have been described in epidermoid cysts in patients with Gardner syndrome [1]. Surgical excision of the pilomatricoma is the treatment of choice, with wide resection margins to minimize the risk of recurrences [2].

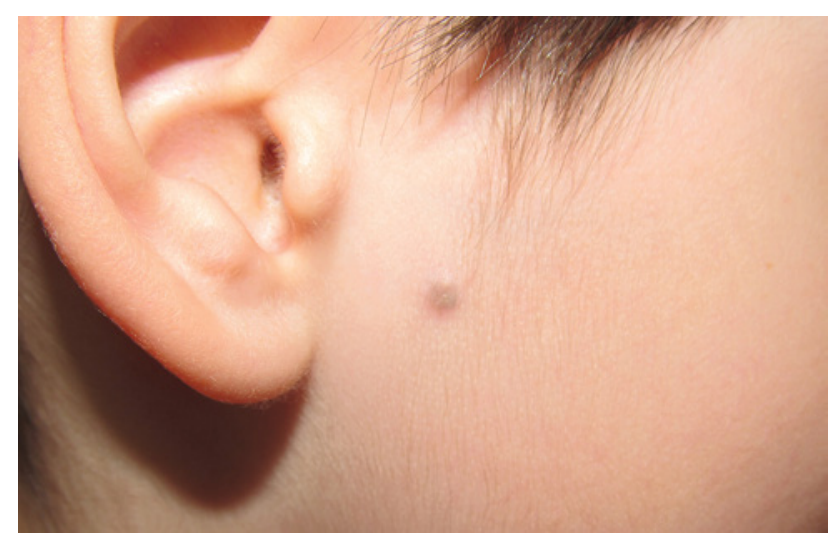

Figure 1. Clinical presentation of a preauricular, firm, solitary lesion on the face of a 6-year-old girl. [Copyright: @2019 Krtanjek et al.]

\section{Case Presentation}

In our case, a 6-year-old girl presented clinically with a preauricular, firm, solitary lesion that had been growing slowly for the 2 months before the first visit (Figure 1). Dermoscopy 


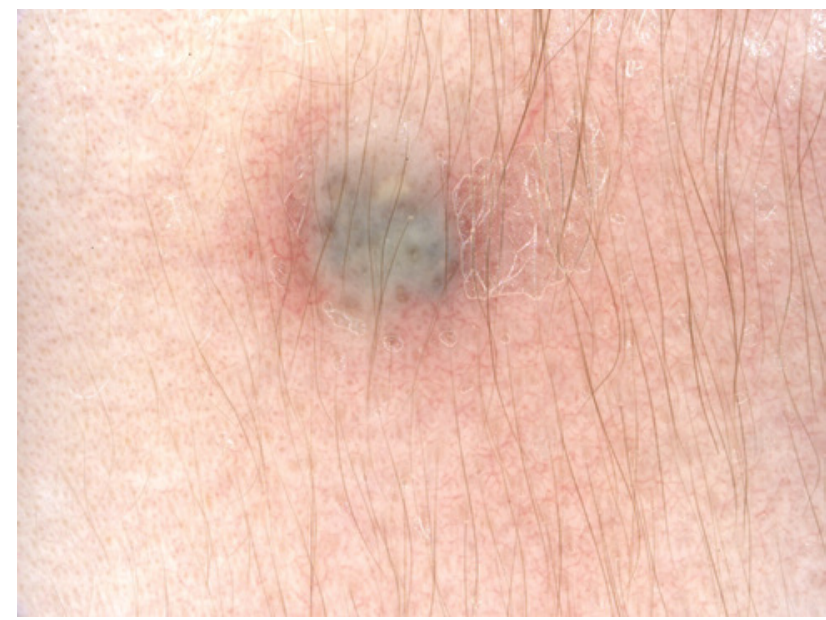

Figure 2. Dermoscopy image of the lesion (Dermlite 3Gen PRO HR II, Nikon Coolpix). Erythematous surrounding skin, irregular white structures, and brown-blue central pigmentation. [Copyright: (C)2019 Krtanjek et al.]

revealed erythematous border, irregular white structures, and brown-blue central pigmentation (Figure 2).

Based on the clinical and dermoscopic examination, the initial diagnosis was pilomatricoma with differential diagnosis of foreign body reaction. After 1 month, the lesion enlarged quickly; therefore, excision was advised. Histopathology report demonstrated a cyst lined by an epidermislike epithelium including a granular cell layer, filled with laminated keratin, compatible with a diagnosis of epidermal cyst (Figure 3).

\section{Conclusions}

We believe that this is the first report of an epidermal cyst on the face of a child with these dermoscopic features. Given

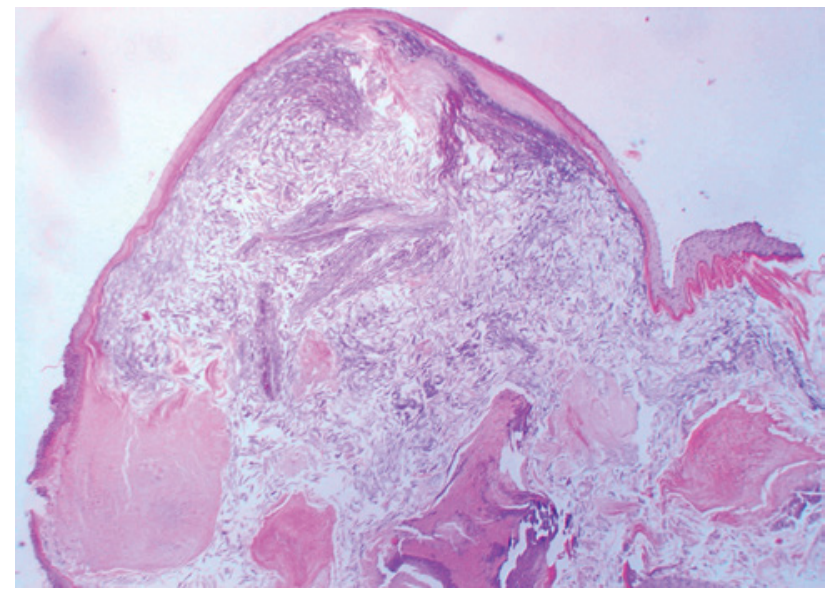

Figure 3. A cyst lined by an epidermis-like epithelium including a granular cell layer, filled with laminated keratin. [Copyright: (02019 Krtanjek et al.]

its frequent incidence, this diagnosis should be considered when evaluating similar skin lesions, to avoid unnecessary surgical excision.

\section{References}

1. Ghigliotti G, Cinotti E, Parodi A. Usefulness of dermoscopy for the diagnosis of epidermal cyst: the 'pore' sign. Clin Exp Dermatol. 2014;39(5):649-650.

2. Fernández Atuan R, Álvarez García N, González Ruiz Y, Siles Hinojosa A, Rihuete Heras MA, Elías Pollina J. The diagnosis of pilomatrixoma in children is not as easy as it may seem: a review of 126 cases [in Spanish]. Cir Pediatr. 2017;30(1):46-49. 